\title{
Specific serotonergic reuptake inhibition impairs vigilance performance acutely and after subchronic treatment.
}

Citation for published version (APA):

Riedel, W. J., Eikmans, K. J. L., Heldens, A., \& Schmitt, J. A. J. (2005). Specific serotonergic reuptake inhibition impairs vigilance performance acutely and after subchronic treatment. Journal of Psychopharmacology, 19, 12-20. https://doi.org/10.1177/0269881105048887

Document status and date:

Published: 01/01/2005

DOI:

10.1177/0269881105048887

Document Version:

Publisher's PDF, also known as Version of record

\section{Document license:}

Taverne

Please check the document version of this publication:

- A submitted manuscript is the version of the article upon submission and before peer-review. There can be important differences between the submitted version and the official published version of record.

People interested in the research are advised to contact the author for the final version of the publication, or visit the DOI to the publisher's website.

- The final author version and the galley proof are versions of the publication after peer review.

- The final published version features the final layout of the paper including the volume, issue and page numbers.

Link to publication

\footnotetext{
General rights rights.

- You may freely distribute the URL identifying the publication in the public portal. please follow below link for the End User Agreement:

www.umlib.nl/taverne-license

Take down policy

If you believe that this document breaches copyright please contact us at:

repository@maastrichtuniversity.nl

providing details and we will investigate your claim.
}

Copyright and moral rights for the publications made accessible in the public portal are retained by the authors and/or other copyright owners and it is a condition of accessing publications that users recognise and abide by the legal requirements associated with these

- Users may download and print one copy of any publication from the public portal for the purpose of private study or research.

- You may not further distribute the material or use it for any profit-making activity or commercial gain

If the publication is distributed under the terms of Article 25fa of the Dutch Copyright Act, indicated by the "Taverne" license above, 


\section{Specific serotonergic reuptake inhibition impairs vigilance performance acutely and after subchronic treatment}

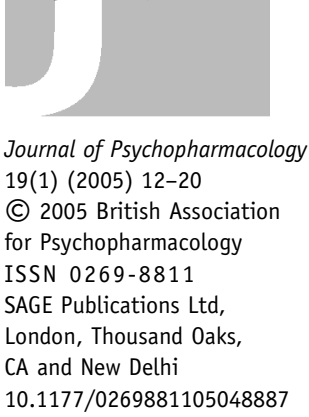

Wim J. Riedel Experimental Psychopharmacology Unit, Brain and Behaviour Institute, Faculty of Psychology, Universiteit Maastricht, The Netherlands.

Karin Eikmans Experimental Psychopharmacology Unit, Brain and Behaviour Institute, Faculty of Psychology, Universiteit Maastricht, The Netherlands.

Annet Heldens Experimental Psychopharmacology Unit, Brain and Behaviour Institute, Faculty of Psychology, Universiteit Maastricht, The Netherlands.

Jeroen A. J. Schmitt Nutrition and Health Department, Nestle Research Center, Lausanne, Switzerland.

\begin{abstract}
Subchronic treatment with the selective serotonergic reuptake inhibitors (SSRIs) fluoxetine, venlafaxine and paroxetine, but not sertraline, were previously shown to specifically impair vigilance performance. The current study was designed to compare the vigilance effects of subchronic treatment with the SSRIs sertraline and citalopram in healthy volunteers, according to a placebo-controlled, double-blind, three-way cross-over design. Twenty-four healthy subjects, aged 30-50 years, of whom 21 completed the study, underwent three treatment periods of 2 weeks in which they received sertraline $(50 \mathrm{mg}$ on days $1-8,100 \mathrm{mg}$ on days 8-15), citalopram (20 mg on days $1-8,40 \mathrm{mg}$ on days 8-15) and placebo. Treatment periods were separated by 14 days washout periods. Vigilance performance was assessed through a 45-min Mackworth Clock Test at days 1, 8 and 15 of each treatment period. It was found
\end{abstract}

that citalopram impaired vigilance performance acutely after the first $20 \mathrm{mg}$ dose and subchronically after $40 \mathrm{mg}$ daily doses. By contrast, no vigilance impairment was found during sertraline treatment. Sertraline is the only SSRI studied so far with no detrimental effects on vigilance. This may be due to the affinity of sertraline for the dopamine reuptake site. Because citalopram is the most specific SSRI showing this effect, it is concluded that the SSRI-induced decrement of vigilance performance is specifically associated with serotonergic reuptake inhibition.

\section{Keywords}

citalopram, cognitive function, serotonin-drug-effects, sertraline, SSRIs, vigilance

\section{Introduction}

Vigilance decrements after acute and subchronic antidepressant administration have been reported in healthy volunteers after acute and subchronic treatment with the serotonergic reuptake inhibitors (SSRIs) fluoxetine (Ramaekers et al., 1995), venlafaxine (O'Hanlon et al., 1998) and paroxetine (Schmitt et al., 2002). This has led to the hypothesis that impairment of vigilance performance is associated specifically with serotonergic reuptake inhibition. The effect can be assessed after acute as well as after subchronic administration of 1-3 weeks. With the exception of sertraline, all SSRIs studied to date have been shown to impair vigilance performance using the classical Mackworth clock task (Mackworth, 1948). Briefly, the Mackworth Clock is a task that challenges continuous alertness for rare events. The Mackworth Clock Test was developed as a model to evaluate vigilance in British Air Force radar technicians during World War II (Mackworth, 1948). Subjects have to watch a clock over a continuous period of 45 min for an irregular 2-s instead of a regular 1-s jump, which on average occurs once in every $90 \mathrm{~s}$. Previous studies have shown that all antidepressants including SSRIs impair performance on this task (Ramaekers et al., 1995; Ramaekers et al., 1998). However, although the impairment observed after tricyclic and secondgeneration antidepressants such as dothiepin and mianserin, 
respectively, can be interpreted as non-specific expressions of sedation, the vigilance impairment observed after acute and subchronic SSRI treatment in healthy volunteers appears to be highly specific because it is the only robust performance effect that this class of drugs appears to induce. The highly specific vigilance decrements after subchronic serotonergic drug treatment can be explained by the inhibitory effect of serotonin (5-HT) upon other neurotransmission systems maintaining arousal (i.e. the noradrenergic, cholinergic and dopaminergic systems) (Jacobs and Fornal, 1995; Robbins, 1997). It has been suggested that subtle, but significant, affinities in SSRIs for other receptor systems (paroxetine: anticholinergic; sertraline: dopamine reuptake inhibition; venlafaxine: noradrenergic reuptake inhibition) exist and that these may explain subtle cognitive effects such as the observed long-term memory impairment after subchronic paroxetine (Schmitt et al., 2001), and possibly also the absence of the vigilance decrement in sertraline. In the present study, we investigated whether citalopram, the most specific serotonergic drug among SSRIs, would also impair vigilance and how this compares to the vigilance effects of sertraline.

Citalopram has rarely been studied with regard to its effects on cognitive and psychomotor function. One study reported an absence of acute and subchronic cognitive and psychomotor effects of citalopram 10, 20 and $40 \mathrm{mg}$ doses administered for 8 days in healthy volunteers (Fairweather et al., 1997). On the basis of previous studies with other SSRIs, it would be expected that the same vigilance decrements are found in citalopram as those in fluoxetine, venlafaxine and paroxetine.

The absence of impaired vigilance performance after sertraline has been explained by the affinity of sertraline to block dopamine reuptake sites (Bolden-Watson and Richelson, 1993), and hence its property to increase dopaminergic neurotransmission. The arousal function of the dopaminergic system is characterized by that of behavioural activation (Robbins, 1997). A decline of dopamine has been proposed to underlie the classical vigilance decrement and therefore dopamine-promoting drugs are recognized as the major agents to counteract the vigilance decrement (Nicholson et al., 1990). Although vigilance decrements are classically explained through an impairment of arousal caused by a lack of novel sensory input, the role of frontal executive functions (monitoring) are important as well. It is assumed that dopaminergic pathways play a major role in these functions. In our most recent study, we showed that retrieval from semantic memory, as assessed with the word fluency test, was enhanced in healthy volunteers aged 30-50 years, after subchronic sertraline administration relative to placebo. This improvement was not seen after paroxetine (Schmitt et al., 2001). The explanation foor this effect could lie in a relatively enhanced dopaminergic function because this is important in executive, frontal lobe functions such as memory retrieval. The present study aimed to demonstrate that subtle differences in pharmacological profiles among the SSRIs sertraline and citalopram have demonstrable and differential behavioural effects on vigilance performance, as well as performance on tests of memory and psychomotor function.

We hypothesized impairment of vigilance performance as determined by performance on the Mackworth Clock test in healthy middle-aged volunteers after treatment with therapeutic doses of citalopram in comparison with placebo on days 1,8 and 15 of treatment, respectively.

Secondarily, we investigated the same hypothesis for an effect of sertraline on Mackworth clock performance. Furthermore, we investigated if citalopram and sertraline had any effect on performance in other cognitive and psychomotor tasks.

\section{Materials and methods}

\section{Subjects}

Twenty-four healthy volunteers of both sexes, aged 30-50 years, participated in the study (Table 1). Screening included a telephone interview, health questionnaire, 12-lead electrocardiogram, laboratory tests (blood haematology and chemistry, urinalysis, drug and pregnancy screening) and a routine medical examination. Exclusion criteria were the presence or a history, cardiac, hepatic, renal, pulmonary, neurological, gastrointestinal, haematological or psychiatric illness, symptoms excessive drinking ( $>20$ units of alcohol per week) pregnancy or lactation, use of medication other than oral contraceptives, use of drugs, and any sensory or motor deficits which could reasonably be expected to affect test performance. All subjects scored below depression threshold $(<50)$ on the Zung Depression Scale (Zung, 1965). The study was approved by the standing Medical Ethics Committee of Maastricht University, and carried out in accordance with the Declaration of Helsinki (Hong Kong Modification, 1989). Written informed consent was obtained from each subject prior to participation.

\section{Experimental design}

Double-blind, placebo-controlled, three-way cross-over study. Complete balancing of the treatment orders yielded six treatment orders distributed over 24 subjects.

\section{Treatment}

Treatment orders were randomly assigned and double-blind. Treatment periods lasted 15 days and were separated by 13-day washout periods. Treatment regimens consisted of sertraline $50 \mathrm{mg}$ o.d. on days $1-8$, followed by sertraline $100 \mathrm{mg}$ o.d. on days $9-15$; citalopram $20 \mathrm{mg}$ o.d. on days $1-8$, followed by citalopram $40 \mathrm{mg}$ o.d. on days 9-15, or placebo. Medication was taken at fixed times

Table 1 Subject variables

\begin{tabular}{lcc}
\hline & Mean \pm SE & Min - Max \\
\hline Males/females & $11 / 10$ & \\
Age (years) & $40.3 \pm 1.1$ & $30-49$ \\
Level of edcucation (1-7) & $2.6 \pm 0.4$ & $1-6$ \\
Body mass index (weight/length ${ }^{2}$ ) & $24.9 \pm 0.7$ & $20-32$ \\
Zung Depression Score & $28.7 \pm 1.5$ & $21-46$ \\
\hline
\end{tabular}

Data are mean \pm SE. 
in the morning in one capsule during the first week and two capsules during the second week. At the investigated daily dosages, which typical resemble start dose regimens in clinically depressed patients, both SSRIs are equally efficacious in the treatment of major depression (Goodnick and Goldstein, 1998).

\section{Procedure}

All medication was taken orally either always at $08.00 \mathrm{~h}$ (subjects $2,15,18,20,21,22,23,24$ ), at $10.00 \mathrm{~h}$ (subjects 1, 5, 6, 9, 10, 12, $13,14)$ or at $12.00 \mathrm{~h}$ (subjects $3,4,7,8,11,16,17,19)$. Assessments were always carrried out starting $4 \mathrm{~h}$ after drug administration and lasting until $6 \mathrm{~h}$ after drug administration. Blood samples for drug levels were taken $6 \mathrm{~h}$ after drug administration.

Assessments were done on days 1,8 and 15 of each treatment period on a fixed time between $12.00 \mathrm{~h}$ and $18.00 \mathrm{~h}$. Before the start of the study, all subjects were individually trained to practice cognitive tests. Consumption of alcoholic beverages during the treatment periods was prohibited and subjects were instructed to arrive at the laboratory well rested. Female subjects were tested for pregnancy before the start of each the three treatment periods. The entire procedure lasted approximately $2 \mathrm{~h}$.

Upon arrival, subjects completed the Groningen Sleep Quality Scale (see below) and were then seated in a soundproof test room. They first completed the word learning and reaction time tests (see below). Subsequently, vigilance performance was assessed using a 45-min Mackworth Clock Test (see below). Finally, a $10 \mathrm{ml}$ blood sample was taken.

\section{Cognitive test battery}

Mackworth Clock Test (Mackworth, 1948) This test has been extensively used in studies on human vigilance performance. Subjects were seated in front of a computer screen displaying a circular arrangement of 60 dots simulating the second marks on a clock. Dots were briefly illuminated in clockwise rotation at a rate of one per $500 \mathrm{~ms}$. Usually the rotation proceeded with a $6^{\circ}$ jump. Subjects were instructed that at rare, irregular intervals the target would proceed with a $12^{\circ}$ jump by skipping one of the dots in the normal sequence. This double jump was the signal to which subjects were required to respond by pressing a button as quickly as possible. A response made within $4 \mathrm{~s}$ after the occurrence of a signal was registered as a correct detection. A total of 30 signals were presented during the 45-min task. Ten signals occurred within each successive 15 -min period, with intervals ranging from $8 \mathrm{~s}$ to $7.2 \mathrm{~min}$. Outcome measures were the number of correct detections and the corresponding reaction times, and the number of false detections.

Word Learning Test (Riedel et al., 1999a) This test is an adapted version of the Rey Auditory Verbal Learning Test (Lezak, 1995). The test consists of a list of 30 monosyllabic words (18 nouns and 12 adjectives), which are presented in three trials on a computer screen. Items are presented in the same sequence at a rate of one per $2 \mathrm{~s}$. Each trial ends with a free recall of the words (immediate recall). Thirty minutes after the third trial, the subject is requested to recall as many words as possible (delayed recall). A Yes/No recognition test, consisting of 15 former words and 15 new but comparable words, is given after the delayed recall test. The words remain on the screen for $2000 \mathrm{~ms}$ or until the subject responds. Another $1000 \mathrm{~ms}$ elapse before the next word appears on the screen. After presentation of each word the subject has to respond 'Yes/No' as fast as possible to indicate recognition of the word (delayed recognition). The reaction times (RTs) are recorded. There are two different recognition lists to probe the long term retention of each 30 word list. Both recognition lists consist of 15 formerly learned and 15 new words (distractors). According to the theory of signal detection (Pollack and Norman, 1964), the proportion of correctly recognized words $(\mathrm{cr})$ and the proportion of falsely recognized $(f r)$ constitute the nonparametric sensitivity measure: $A^{\prime}=1-1 / 4[f r / c r+(1-\mathrm{cr}) /(1-f r)] . A^{\prime}$ is in fact the proportion of correctly recognized words, corrected for the subject's response tendency. Because the distribution of $A^{\prime}$ is skewed due to a ceiling effect, $A^{\prime}$ should be arcsin transformed before being used in statistical analysis. The variables used are the total number of words recalled after the first three trials as a measure of short-term memory, the number of correct words on delayed free recall as a measure of retrieval from long-term memory (LTM), $A^{\prime}$ as a measure of storage in LTM, and the median RT of correctly recognized target words as a measure of speed of retrieval from LTM. There are six parallel lists, comparable with regard to their level of abstraction and the affective tone of the words. The six lists of 30 words, each contain 18 nouns and 12 adjectives. All words are monosyllabic and meaningful. The words were chosen from a list of 600 words. The lists are comparable with respect to their amount of abstraction. For each recognition version, 15 target words were taken, to which 15 distractor words were added. Both the target words and the distractors are similar in their level of abstraction.

Simple- and choice-reaction time (Houx and Jolles, 1993) This is a computerized test, in which reaction times are studied as a function of the complexity of task requirements. In addition, the speed and accuracy of arm movements over short trajectories are also studied. The subject held one button and was asked to press one of five other buttons located equidistantly from the hold button when lit. This yielded reaction times consisting of an initiation phase (time from stimulus onset until release of the hold button) and a movement phase (time from release of the hold button until the response button is pushed). The response set consisted of pressing the one button that lit up (simple RT), pressing one of three buttons which lit up (three-choice RT), or pressing the button to the right of the lit button (Stimulus-Response incompatible threechoice RT) as quickly as possible. Initiation times and movement times thus comprised the dependent variables obtained for each of the three reaction time tasks. This task measures sensorimotor speed, choice-reaction speed, and choice-reaction speed with response competition.

Profile of Mood States (POMS) (McNair et al., 1992) The POMS is a self-evaluation scale for short, alternating states. The POMS consists of 72 adjectives comprising six bipolar mood factors (Energetic-Tired, Elated-Depressed, Agreeable-Hostile, 
Confident-Unsure, Composed-Anxious and ClearheadedConfused). Next to each adjective is a five-point scale. In this way, the respondent can indicate in what amount these items are appropriate to his/her mood.

Subjective Sleep Quality Subjective quality of sleep was assessed using the Groningen Sleep Quality Questionnaire (MulderHajonides-van-der-Meulen, 1981). This questionnaire consists of 14 items denoting statements regarding the quality of sleep over the past week. The items are transitive and refer to sleep problems of increasing severity and hence form a Gutman-Scale, but its items are presented in random order. Subjects agreed or disagreed with each of the statements. Maximum score is 14 , indicating severely disturbed sleep, and minimum score is 0 , indicating no sleep problems.

\section{Blood sampling}

Blood $(10 \mathrm{ml})$ was collected by venipuncture on days 1,8 and 15 at the end of each cognitive test battery. Blood samples obtained in the citalopram and sertraline periods were assayed for the appropriate drug using a reverse phase high-performance liquid chromatography procedure with ultraviolet detection, with a detection limit of $10 \mathrm{ng} / \mathrm{ml}$ for the citalopram assay and $5 \mathrm{ng} / \mathrm{ml}$ for the sertraline assay.

\section{Statistical analysis}

The primary outcome measure, correct detections on the Mackworth Clock Task, was evaluated using repeated measures ANOVA of the vigilance assessments at days 1, 8 and 15 for the comparison between citalopram and placebo. Due to the one-sided nature of the prediction of impairment after citalopram, only in this primary endpoint evaluation, one-tailed significance testing was carried out. All other evaluations were carried out in a similar fashion, but were tested two-tailed and $\alpha=0.05$ in all cases.

The number of subjects is sufficient to detect a performance impairment of one target out of 30 in the Mackworth Clock Vigilance Task (Ramaekers et al., 1995; O'Hanlon et al., 1998; Schmitt et al., 2002). This impairment can be considered safety relevant because it resembles an extra amount of time of inattention or 'off the job' of 2 min per hour as a result of drug sideeffects, which is enough time for the incipience of accidents.

\section{Results}

Twenty-one subjects completed the study. Three subjects (one male and two females) did not complete the study due to sideeffects. One male subject stopped participation after the first dose of citalopram $20 \mathrm{mg}$, which happened to be the first dose in the

Table 2 Cognitive measures on days 1, 8 and 15 of placebo, sertraline and citalopram treatment

\begin{tabular}{|c|c|c|c|c|c|}
\hline Task & Outcome parameter & Treatment & $\begin{array}{l}\text { Day } 1 \\
\text { (acute effect } \\
\text { of low dose) }\end{array}$ & $\begin{array}{c}\text { Day } 8 \\
\text { (subchronic } \\
\text { effect low dose) }\end{array}$ & $\begin{array}{c}\text { Day } 15 \\
\text { (subchronic effect } \\
\text { high dose) }\end{array}$ \\
\hline \multirow[t]{12}{*}{ Word list learning } & \multirow{3}{*}{$\begin{array}{l}\text { Maximum no. words } \\
\text { immediate recall }\end{array}$} & Placebo & $15.9 \pm 1.0$ & $12.9 \pm 0.8$ & $12.7 \pm 0.8$ \\
\hline & & Sertraline & $16.7 \pm 1.3$ & $13.1 \pm 0.8$ & $14.0 \pm 1.0$ \\
\hline & & Citalopram & $16.9 \pm 1.2$ & $13.0 \pm 1.0$ & $12.9 \pm 0.9$ \\
\hline & No. words & Placebo & $12.4 \pm 1.4$ & $11.1 \pm 1.2$ & $12.0 \pm 1.2$ \\
\hline & \multirow[t]{2}{*}{ delayed recall } & Sertraline & $13.6 \pm 1.5$ & $11.3 \pm 1.0$ & $11.5 \pm 1.5$ \\
\hline & & Citalopram & $12.8 \pm 1.4$ & $10.9 \pm 1.4$ & $10.5 \pm 1.3$ \\
\hline & $\%$ Correct words & Placebo & $27.0 \pm 0.5$ & $25.6 \pm 0.6$ & $25.4 \pm 0.6$ \\
\hline & \multirow[t]{2}{*}{ delayed recognition } & Sertraline & $25.4 \pm 1.1$ & $25.9 \pm 0.5$ & $25.6 \pm 0.6$ \\
\hline & & Citalopram & $26.1 \pm 0.7$ & $25.4 \pm 0.7$ & $25.9 \pm 0.5$ \\
\hline & RT delayed & Placebo & $810 \pm 20$ & $814 \pm 19$ & $792 \pm 20$ \\
\hline & \multirow[t]{2}{*}{ recognition (ms) } & Sertraline & $798 \pm 17$ & $836 \pm 28$ & $794 \pm 19$ \\
\hline & & Citalopram & $803 \pm 21$ & $821 \pm 18$ & $823 \pm 22$ \\
\hline \multirow{12}{*}{$\begin{array}{l}\text { Motor and choice } \\
\text { reaction time }\end{array}$} & Movement & Placebo & $118 \pm 5$ & $115 \pm 4$ & $113 \pm 5$ \\
\hline & \multirow[t]{2}{*}{ time (ms) } & Sertraline & $114 \pm 5$ & $114 \pm 5$ & $113 \pm 5$ \\
\hline & & Citalopram & $110 \pm 4$ & $113 \pm 4$ & $112 \pm 5$ \\
\hline & \multirow[t]{3}{*}{ Simple RT (ms) } & Placebo & $309 \pm 8$ & $300 \pm 7$ & $297 \pm 6$ \\
\hline & & Sertraline & $304 \pm 9$ & $292 \pm 8$ & $294 \pm 7$ \\
\hline & & Citalopram & $296 \pm 9$ & $290 \pm 8$ & $291 \pm 8$ \\
\hline & \multirow[t]{3}{*}{ Chioce RT (ms) } & Placebo & $364 \pm 11$ & $361 \pm 8$ & $357 \pm 9$ \\
\hline & & Sertraline & $356 \pm 8$ & $359 \pm 9$ & $352 \pm 8$ \\
\hline & & Citalopram & $351 \pm 8$ & $347 \pm 9$ & $350 \pm 7$ \\
\hline & Improbable choice & Placebo & $447 \pm 14$ & $444 \pm 14$ & $433 \pm 14$ \\
\hline & \multirow[t]{2}{*}{$\mathrm{RT}(\mathrm{ms})$} & Sertraline & $437 \pm 17$ & $429 \pm 15$ & $436 \pm 16$ \\
\hline & & Citalopram & $435 \pm 13$ & $428 \pm 14$ & $430 \pm 13$ \\
\hline
\end{tabular}

Data are mean \pm SE. RT, Reaction time. 
Table 3 Subjective measures on days 1, 8 and 15 of placebo, sertraline and citalopram treatment

\begin{tabular}{|c|c|c|c|c|c|}
\hline Task & Outcome parameter & Treatment & $\begin{array}{l}\text { Day } 1 \\
\text { (acute effect } \\
\text { of low dose) }\end{array}$ & $\begin{array}{c}\text { Day } 8 \\
\text { (subchronic } \\
\text { effect low dose) }\end{array}$ & $\begin{array}{c}\text { Day } 15 \\
\text { (subchronic effect } \\
\text { high dose) }\end{array}$ \\
\hline \multirow{12}{*}{$\begin{array}{l}\text { Subjective } \\
\text { sleep measures }\end{array}$} & \multirow[t]{3}{*}{ No. complaints } & Placebo & $2.6 \pm 0.7$ & $3.2 \pm 0.9$ & $1.7 \pm 0.6$ \\
\hline & & Sertraline & $2.0 \pm 0.7$ & $2.5 \pm 0.5$ & $3.8 \pm 0.9$ \\
\hline & & Citalopram & $2.1 \pm 0.7$ & $2.9 \pm 1.0$ & $3.3 \pm 0.7$ \\
\hline & Sleep & Placebo & $15 \pm 3$ & $22 \pm 9$ & $14 \pm 3$ \\
\hline & \multirow[t]{2}{*}{ latency (min) } & Sertraline & $11 \pm 2$ & $15 \pm 3$ & $25 \pm 9$ \\
\hline & & Citalopram & $16 \pm 4$ & $15 \pm 4$ & $17 \pm 3$ \\
\hline & Sleep & Placebo & $7.1 \pm 0.2$ & $6.7 \pm 0.4$ & $7.4 \pm 0.2$ \\
\hline & \multirow[t]{2}{*}{ duration (h) } & Sertraline & $7.3 \pm 0.3$ & $7.2 \pm 0.3$ & $6.9 \pm 0.3$ \\
\hline & & Citalopram & $7.3 \pm 0.2$ & $7.1 \pm 0.3$ & $7.1 \pm 0.3$ \\
\hline & \multirow[t]{3}{*}{ No. awakenings } & Placebo & $1.0 \pm 0.3$ & $1.0 \pm 0.3$ & $0.7 \pm 0.3$ \\
\hline & & Sertraline & $0.7 \pm 0.2$ & $1.0 \pm 0.3$ & $1.1 \pm 0.4$ \\
\hline & & Citalopram & $0.6 \pm 0.3$ & $1.0 \pm 0.3$ & $1.6 \pm 0.4$ \\
\hline \multirow{15}{*}{$\begin{array}{l}\text { Profile of } \\
\text { mood states }\end{array}$} & \multirow[t]{3}{*}{ Depression (0-100) } & Placebo & $14 \pm 3$ & $16 \pm 4$ & $18 \pm 3$ \\
\hline & & Sertraline & $19 \pm 4$ & $19 \pm 3$ & $19 \pm 3$ \\
\hline & & Citalopram & $17 \pm 3$ & $17 \pm 3$ & $17 \pm 4$ \\
\hline & \multirow[t]{3}{*}{ Anger (0-100) } & Placebo & $14 \pm 2$ & $16 \pm 3$ & $19 \pm 4$ \\
\hline & & Sertraline & $19 \pm 4$ & $20 \pm 3$ & $20 \pm 4$ \\
\hline & & Citalopram & $18 \pm 3$ & $18 \pm 3$ & $18 \pm 4$ \\
\hline & \multirow[t]{3}{*}{ Fatigue $(0-100)$} & Placebo & $21 \pm 4$ & $23 \pm 4$ & $23 \pm 4$ \\
\hline & & Sertraline & $30 \pm 5$ & $27 \pm 4$ & $27 \pm 4$ \\
\hline & & Citalopram & $25 \pm 4$ & $26 \pm 4$ & $29 \pm 4$ \\
\hline & \multirow[t]{3}{*}{ Vigour (0-100) } & Placebo & $83 \pm 4$ & $79 \pm 4$ & $78 \pm 4$ \\
\hline & & Sertraline & $74 \pm 4$ & $75 \pm 4$ & $75 \pm 4$ \\
\hline & & Citalopram & $77 \pm 4$ & $77 \pm 4$ & $73 \pm 4$ \\
\hline & \multirow[t]{3}{*}{ Tension $(0-100)$} & Placebo & $16 \pm 3$ & $17 \pm 3$ & $20 \pm 4$ \\
\hline & & Sertraline & $21 \pm 4$ & $21 \pm 4$ & $20 \pm 3$ \\
\hline & & Citalopram & $18 \pm 3$ & $18 \pm 3$ & $19 \pm 3$ \\
\hline
\end{tabular}

Data are mean \pm SE.

first session. This subject complained about nausea and diarrhoea. One female subject also halted participation after the first dose of citalopram $20 \mathrm{mg}$, which happened in the third treatment period (meaning that she did finish the other two conditions). She complained about nausea and lightheadedness. Another female subject stopped after the eight daily dose of citalopram $20 \mathrm{mg}$ and completed the other treatments. She complained about nausea and loss of appetite. All these subjects' complaints were said to be of a serious nature, such that they led to their decision to halt the respective treatment conditions, which all turned out to be citalopram $20 \mathrm{mg}$.

Performance and mood results are shown in Tables 2 and 3, respectively.

\section{Mackworth Clock}

Analysis of the number of correct responses over the 45-min vigilance task showed that citalopram reduced the number of correct responses $[F(1,20)=3.4, p=0.041]$ (Fig. 1). Sertraline did not significantly affect correct responses in the vigilance task. No main effect of Treatment by Day emerged from either drug-placebo comparison. Reaction times for the correct responses showed that sertraline accelerated responses $[F(1,20)=5.7, p=0.027]$.

\section{Simple- and Choice RT}

There was no main effect of citalopram on RT in either of the three subtasks, but there was a treatment by day interaction which seemed to indicate that citalopram speeded overall RT on the first day of treatment and that the effect subsided as treatment duration continued $[F(1,20)=5.1, p=0.035]$. A similar effect of citalopram on 3-choice RT $[F(1,20)=5.6, p=0.029]$ was seen in the absence of treatment by day interactions.

\section{Word list}

No effects on immediate recall were seen. Citalopram impaired delayed recall on day 15 as indicated by a significant treatment by day interaction $[F(1,20)=5.5, p=0.030]$. No other effects on delayed recall were seen. No significant effects were seen on recognition parameters.

\section{Subjective Sleep Questionnaire}

No treatment effects or interactions were seen on subjective sleep quality, sleep latency and sleep duration. 
VIGLANCE ACCURACY

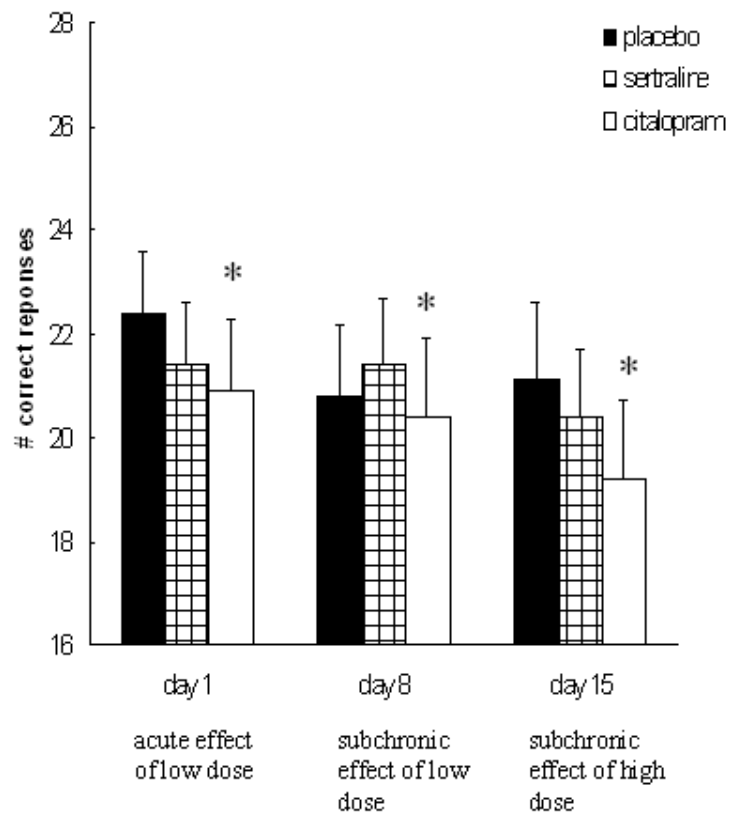

VIGILANCE SPEED

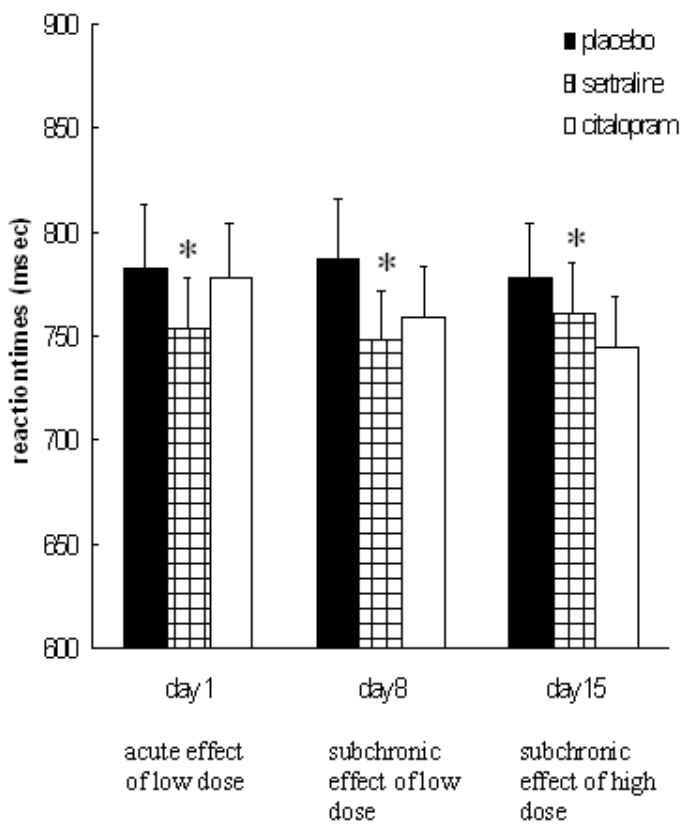

Figure 1 Mean \pm SE number of correct responses (left) and the corresponding response times (right) in the Mackworth vigilance task following 1, 8 and 15 days of treatments with placebo, sertraline and citalopram. ${ }^{*} p<0.05$ versus placebo

\section{Profile of Mood States}

Sertraline $[F(1,20)=5.1, p=0.036]$ and citalopram $[F(1,20)=7.0$, $p=0.016]$ decreased feelings of vigour. Citalopram $[F(1,20)=5.0$, $p=0.038]$ increased feelings of fatigue. No effects were observed on the POMS dimensions depression, anger and tension.

\section{Drug plasma levels}

Plasma levels [main effect: $F(2,19)=124, p<0.0001$ ] of sertraline $[F(1,20)=98, p<0.001]$ and citalopram $[F(1,20)=244, p<0.001]$

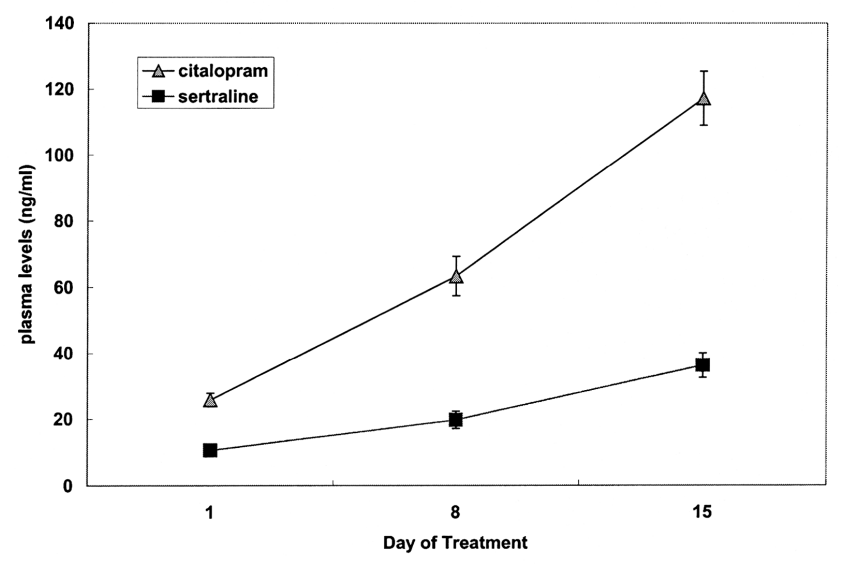

Figure 2 Drug plasma levels significantly differed from zero from the first day of treatment (Fig. 2) and linearly increased throughout the treatment period (interaction effect: $F(2,19)=39, p<0.001]$, both for sertraline $[F(1,20)=61, p<0.001]$ and citalopram $[F(1,20)=164, p<$ $0.001]$.

\section{Effects of gender}

No significant differences emerged between males and females in any of the dependent variables. However, it must be noted that sample sizes were not large enough to conclude absence of gender differences in the observed effects.

\section{Effects of time of day}

No significant differences emerged between subjects tested at different times of day in any of the dependent variables. It seems unlikely that the three cohorts of subjects in whom drug administration and cognitive testing was spaced $2 \mathrm{~h}$ apart has influenced the results.

\section{Effects of treatment order}

Treatment orders were completely counterbalanced for 24 subjects. Two subjects dropped out on citalopram in the first treatment period and one in the third treatment period, rendering a slight imbalance in treatment orders. However, upon inspection of the data, it seems unlikely that this was of any influence on the results. 


\section{Discussion}

Briefly summarizing the results, we note that the prediction that citalopram would impair the primary outcome measure, vigilance performance, was confirmed, albeit that the effect was marginal. As in the previous study (Schmitt et al., 2002), sertraline did not impair vigilance performance. Furthermore, three subjects dropped out from the citalopram condition due to gastric adverse effects of citalopram. Results could not be corrected for this selective dropout. Sertraline speeded reaction times in the Mackworth vigilance task. This was also observed in the previous study (Schmitt et al., 2002). Citalopram tended to impair delayed recall after 2 weeks of treatment and tended to accelerate RT in the choice RT task but, otherwise, no effects on cognition were found. Both SSRIs had no effects on subjective sleep quality, but subjective measures of mood showed that both tended to decrease feelings of vigour and citalopram tended to increase feelings of fatigue. Plasma levels of both drugs were significantly elevated after single doses and remained increased after 1 and 2 weeks of treatment.

\section{Vigilance}

The pharmacological differences between antidepressants studied using the Mackworth Clock vigilance paradigm appear to indicate that enhancing 5-HT in normal individuals consistently impairs vigilance, just as anticholinergic and antihistaminergic drugs tend to. The simultaneous enhancement of noradrenaline with 5-HT in venlafaxine was previously shown not to counteract the vigilance decrement (O'Hanlon et al., 1998). This means that the decrement is not associated with decreased activity of a serotonergicnoradrenergic system or, alternatively, that the noradrenaline reuptake blocking properties of venlafaxine are not strong enough. Although this is the only human study perfomed in vivo that points in this direction, there is abundant evidence from animal studies that noradrenaline is not the critical neurotransmitter specifically associated with the maintenance of vigilance (Delagrange et al., 1993; McGaughy et al., 1997). It is more likely that noradrenaline is associated with phasic arousal, whereas dopamine is more likely to be associated with a tonic readiness to respond (Pribram and McGuinness, 1975; Robbins, 1997). The lack of effect of sertraline on correct detections in the vigilance task and the tendency of sertraline to speed responses in the vigilance task appears to be consistent with the notion that sertraline differs from the other SSRIs mainly in terms of its additional dopaminergic reuptake inhibition properties (Schmitt et al., 2002).

The vigilance effect of SSRIs is not large, but can be considered theoretically and practically relevant. Possible negative effects on vigilant behaviour should be considered when prescribing SSRI treatment, especially to individuals in occupations requiring alert behaviour in monotonous situations over longer periods of time.

\section{Reaction time tasks}

We observed speeding of three-choice RT after citalopram. Such an observation is in line with a previous report showing that the SSRI fluvoxamine accelerated RT and improved information processing per se (Hasbroucq et al., 1997). The authors suggested that fluvoxamine did not act on the processing stages of stimulus preprocessing and response selection, but improved speed of information processing. However, we did not see any significant SSRI-induced changes of movement time, Simple RT and incompatible threechoice RT. Because of the small effect size as well as potential confounding due to multiple testing, the data described here require replication before further interpretations are made and conclusions drawn.

\section{Memory}

In a previous study that was very similar to the current one, we found impaired delayed recall performance after paroxetine, but not sertraline (Schmitt et al., 2001). These results were explained by the non-serotonergic properties of both drugs (i.e. the anticholinergic affinity of paroxetine was taken to account for impaired delayed recall). However, in the present study, we found a tendency of citalopram to impair delayed recall memory after 15 days of treatment. Therefore, we now have to consider the possibility that elevated levels of 5-HT, rather than anticholinergic effects explain delayed recall memory impairment at day 15 of administration of citalopram. This is not directly in line with the recent observation that an acute dose of citalopram $10 \mathrm{mg}$ i.v. facilitated memory consolidation (Harmer, 2002). However, the different dose and route of administration complicate any comparison. Improvement of memory after serotonergic antidepressants has also been reported in clinical studies (Fudge et al., 1990; Riedel et al., 1999b; Levkovitz et al., 2002), but the mechanism remains unknown.

\section{Subjective effects: sleep and mood}

Both citalopram and sertraline reduced vigour and citalopram elevated fatigue, an observation which is in line with others describing a positive association between elevated levels of 5-HT and fatigue in healthy individuals (Struder and Weicker, 2001). These effects of elevated 5-HT on vigour and fatigue might be consistent with the impairment of vigilance performance, especially in the case of fatigue, leaving undecided only whether these POMS items are simply more sensitive then prolonged vigilance performance, or are indicative of a different process, because only citalopram impaired vigilance performance and not sertraline. To investigate whether there was an association between SSRI effects on vigilance and on vigour and fatigue within subjects, analyses of correlations of drug placebo difference scores between vigilance correct detections and POMS items vigour and fatigue were carried out. The pearson correlation coefficients of vigilance with vigour and fatigue were both $r=0.38$ for sertraline on the first day, but these correlations were not significant. All other coefficients were between $r=-0.12$ and $r=0.16$ and were non-significant.

There are no reports that antidepressants improve depressive symptoms in non-depressed patients. However, the cut-off for depression used in the current study (Zung $<50$ ), although 
formally the cut-off used by Zung (1965), will actually permit a fair amount of depressive symptoms to be experienced by the subjects. Note that the maximum score for the Zung is 80 and that in the case of the Beck Depression Inventory, the cut-off for 'notdepressed' of 12 is less than $20 \%$ of the total range of the scale (64). Although we did not collect Zung ratings during the study, it would have been interesting to see if there were any changes in the scores. However, the only alternative measure to answer this question is the POMS depression subscale and, clearly, no changes were detected in this subscale. The POMS depression subscale has been shown to be sensitive to serotonergic manipulations in similar studies in healthy volunteers on tryptophan depletion (Klaassen et al., 1999) and specifically sensitive to discriminate both between depressed and healthy individuals, as well as the effects of a serotonergic agonist, $m$-chlorophenylpiperzine (Riedel et al., 2002). Therefore, it is unlikely that the observed SSRI effects on cognition, fatigue and vigour are mediated through their primary effects on mood.

\section{Plasma drug levels}

Plasma drug levels of citalopram and sertraline that rise throughout the study reflect a high degree of compliance of the subjects in general.

There was a significant inverse association of citalopram plasma with vigilance performance on on the first day. At $3 \mathrm{~h}$ after drug administration, there was a negative correlation of the difference scores of both accuracy of vigilance performance $(r=-0.47$, $p<0.05)$ and speed of response $(r=-0.46, p<0.05)$. The direction of this association indicates that high plasma citalopram concentrations were associated with improved performance and low concentrations with impaired performance. In view of the fact that, on average, the acute effect of citalopram was to impair performance, more detailed inspection of the data shows that of 21 subjects, 12 performed worse after acute citalopram and seven performed better, whereas two showed no change.

After 15 days of citalopram treatment, the association of plasma levels with reaction times had reversed in the opposite direction, indicating that higher levels were now associated with impaiment $(r=+0.44, p<0.05)$.

\section{Clinical relevance}

More work needs to be carried out to confirm whether the present findings can be reproduced in patients. However, occasional reports of sedation in patients on SSRI treatment appear to be supported by the abundant experimental data on SSRIs demonstrating effects on vigilance.

\section{Conclusion}

The main findings of this study are that citalopram impaired vigilance performance. By contrast, no vigilance impairment was found during sertraline treatment. No other cognitive or behavioural effects were found that could account for the effect of citalopram on vigilance.

\section{Acknowledgements}

This study was supported by an unrestricted educational grant to the University of Maastricht from Pfizer Inc., New York.

The study was carried out and completed at The University of Maastricht while all authors were affiliated there full time, WJR and JAJS as employees and $\mathrm{KE}$ and $\mathrm{AH}$ as students. At present WJR is honorarily affiliated to The University of Maastricht and is employed by GlaxoSmithKline, R\&D, UK. JAJS is presently employed at Nestle Research Center, Lausanne, Switzerland.

\section{References}

Bolden-Watson C, Richelson E (1993) Blockade by newly developed antidepressants of biogenic amine uptake into rat brain synaptosomes. Life Sci 52: 1023-1029

Delagrange P, Canu M H, Rougeul A, Buser P, Bouyer J J (1993) Effects of locus coeruleus lesions on vigilance and attentive behaviour in cat. Behav Brain Res 53: 155-165

Fairweather D B, DalPozzo C, Kerr J S, Lafferty S V, Hindmarch I (1997) Citalopram compared to dothiepin and placebo: Effects on cognitive function and psychomotor performance. Hum Psychopharmacol 12: 119-126

Fudge J L, Perry P J, Garvey M J, Kelly M W (1990) A comparison of the effect of fluoxetine and trazodone on the cognitive functioning of depressed outpatients. J Affect Disorders 18: 275-280

Goodnick P J, Goldstein B J (1998) Selective serotonin reuptake inhibitors in affective disorders - II. Efficacy and quality of life. J Psychopharmacol 12: S21-S54

Harmer C J (2002) Acute administration of citalopram facilitates memory consolidation in healthy volunteers. Psychopharmacology (Berl) 163: 106-110

Hasbroucq T, Rihet P, Blin O, Possamai C A (1997) Serotonin and human information processing: fluvoxamine can improve reaction time performance. Neurosci Lett 229: 204-208

Houx P J, Jolles J (1993) Age-related decline of psychomotor speed: Effects of age, brain health, sex and education. Percept Motor Skill 76: 195-211

Jacobs B L, Fornal C A (1995) Serotonin and behavior. a general hypothesis. In Bloom F E, Kupfer D J (eds), Psychopharmacology: The Fourth Generation of Progress. Raven Press Ltd, New York, NY, pp. 461-469

Klaassen T, Riedel W J, Honig A, Van Someren A, Deutz N E P, Van Praag H M (1999) Mood effects of 24-hour tryptophan depletion in healthy first degree relatives of patients with affective disorders. Biol Psychiatry 46: 489-497

Levkovitz Y, Caftori R, Avital A, Richter-Levin G (2002) The SSRIs drug fluoxetine, but not the noradrenergic tricyclic drug desipramine, improves memory performance during acute major depression. Brain Res Bull 58: 345-350

Lezak M D (1995) Neuropsychological Assessment, 3rd edn. Oxford University Press, New York, NY

Mackworth N H (1948) The breakdown of vigilance during prolonged visual search. QJ Exp Psychol 1: 6-21

McGaughy J, Sandstrom M, Ruland S, Bruno J P, Sarter M (1997) Lack of effects of lesions of the dorsal noradrenergic bundle on behavioral vigilance. Behav Neurosci 111: 646-652

McNair D M, Lorr M, Droppleman L F (1992) Manual for the Profile of Mood States (Revised). Educational and Industrial Testing Service, San Diego, CA 
Mulder-Hajonides-van-der-Meulen W R E H (1981) Measurement of subjective sleep quality. International European Sleep Conference. Amsterdam The Netherlands

Nicholson A N, Pascoe P A, Stone B M (1990) The sleep-wakefulness continuum: interactions with drugs which increase wakefulness and enhance alertness. Alcohol Drugs Driving 5: 287-301

O'Hanlon J, Robbe H W J, Vermeeren A, VanLeeuwen C, Danjou P E (1998) Venlafaxine's effects on healthy volunteers' driving, psychomotor, and vigilance performance during 15-day fixed and incremental dosing regimens. J Clin Psychopharmacol 18: 212-221

Pollack I, Norman D A (1964) A non-parametric analysis of recognition experiments. Psychon Sci 1: 125-126

Pribram K H, McGuinness D (1975) Arousal, activation, and effort in the control of attention. Psychol Rev 82: 116-149

Ramaekers J G, Muntjewerff N D, O'Hanlon J F (1995) A comparative study of acute and subchronic effects of dothiepin, fluoxetine and placebo on psychomotor and actual driving performance. $\mathrm{Br} \mathrm{J}$ Clin Pharmacol 39: 397-404

Ramaekers J G, Muntjewerff N D, Van Veggel L M A, Uiterwijk M M C, O'Hanlon J F (1998) Effects of ascending, nocturnal doses of mirtazapine and mianserin on daytime psychomotor and driving performance, and sleep in young, healthy volunteers. Hum Psychopharmacol 13: S87-S97

Riedel W J, Klaassen T, Deutz N E P, Van Someren A, Van Praag H M (1999a) Tryptophan depletion in normal volunteers produces selective impairment in memory consolidation. Psychopharmacol 141: 362-369

Riedel W J, Schoenmakers E, Vermeeren A, O'Hanlon J F (1999b) The influence of trazodone treatment on cognitive functions in outpatients with major depressive disorder. Hum Psychopharmacol 14: 499-508

Riedel W J, Klaassen T, Griez E, Honig A, Menheere P P C A, Van Praag H M (2002) Dissociable hormonal, cognitive and mood responses to neuroendocrine challenge: evidence for receptor-specific serotonergic dysregulation in depressed mood. Neuropsychopharmacology 26: 358-367

Robbins T W (1997) Arousal systems and attentional processes. Biol Psychol 45: 57-71

Schmitt J A J, Kruizinga M, Riedel W J (2001) Non-serotonergic pharmacological profiles and associated cognitive effects of serotonin reuptake inhibitors. J Psychopharmacol 15: 173-179

Schmitt J A J, Ramaekers J G, Kruizinga M J, Van Boxtel M P J, Vuurman E F P M, Riedel W J (2002) Additional dopamine reuptake inhibition attenuates vigilance decrement induced by serotonergic reuptake inhibition in man. J Psychopharmacol 16: 207-214

Struder H K, Weicker H (2001) Physiology and pathophysiology of the serotonergic system and its implications on mental and physical performance. Part II. Int J Sports Med 22: 482-497

Zung W W K (1965) A self rating depression scale. Arch Gen Psychiatry 12: $63-70$ 